\title{
Reconfigurando a los padres. Análisis de estudios locales desde una perspectiva internacional
}

\section{Reconfiguring fathers: interrogating local studies in an international arena}

\author{
Investigadora Responsible: PhD. Lena Dominelli \\ Lena Dominelli, es profesora de School of Applied Social Sciences miembro de la Academy of the Learned Societies for Social Scien- \\ ces 32 Old Elvet Durham, DH1 3HN; lena.dominelli@durham.ac.uk \\ Dr Leslie Brown es Dean Asociado de Investigación en la University of Victoria in Victoria, Canadá. \\ Dr Susan Strega es Profesor Asistente en University of Victoria. \\ Dr. Marilyn Callahan es investigadora en la University of Victoria. \\ Dr Chris Walmsley es Profesor Asistente en Three Rivers University in Kamploops, Canadá.
}

\begin{abstract}
Resumen
Este estudio habla sobre la conceptualización de los padres ausentes, los que a menudo son descritos en forma negativa como personas que descuidan sus responsabilidades financieras y emocionales hacia sus hijos, ya sea que vivan con ellos y se involucren en su cuidado o no lo hagan. Los autores utilizan una investigación conducida previamente por ellos mismos en Canadá occidental, con el objeto de plantear preguntas acerca de la capacidad de transferencia de conceptos desarrollados para ayudar a los padres a entender las relaciones familiares en Occidente, con respecto a quienes pertenecen a otros lugares. Los resultados concluyeron que los profesionales encargados del bienestar de los niños han perdido oportunidades de entablar una relación con los padres en el 'mejor interés del (los) niño(s).' Las consideraciones acerca del 'riesgo' para las madres, niños y profesionales parecieron pesar más que aquellas que implicaban pensar en forma creativa acerca de lo que los padres pueden ofrecer y de cuáles condiciones, aparte de evitar el contacto, respaldarian en mejor forma los derechos de los niños de vincularse con ambos padres en seguridad y tranquilidad. Los resultados piden una 'reconfiguración' del entendimiento preponderante acerca de esos padres y cuestionar aquellas imágenes que los tratan como personas poco interesadas en el bienestar de sus hijos.
\end{abstract}

Palabras clave (Padres ausentes, derechos de los padres, responsabilidades de las madres, interés de los niños, entendimiento preponderante.)

\begin{abstract}
This study discuss the conceptualisation about absent fathers, who are usually described negatively as neglecting their financial and emotional responsibilities to the children they have whether or not they are living with them or involved in their care. The authors draw upon a study of fathers they conducted in Western Canada to raise questions about the transferability of concepts developed to help them understand family relationships in the West to those pertaining elsewhere. The results concluded that there are lost opportunities for child welfare professionals to engage with these fathers in the 'best interests of the child(ren).' Considerations about 'risk' to mothers, children and practitioners seemed to outweigh those involving thinking creatively about what the fathers could offer and what conditions other than non-contact would best support the children's rights to relate to both their parents in safety and comfort. The results call to 'reconfigure' hegemonic understandings about fathers and to challenge images that treat them as uninterested in children's welfare.
\end{abstract}

Key words (Absent fathers, fathers' rights, mothers' responsibilities, children's interest, hegemonic understanding.) 


\section{Introducción}

El lugar de los padres en las sociedades occidentales ha ido cambiando en respuesta a las presiones socioeconómicas, a los cambiantes esquemas de relaciones al interior de las diversas formas de familias y a las demandas de las feministas en relación a al involucramiento de los hombres en la crianza de los niños junto con las mujeres. Clave en los discursos realizados en países como los Estados Unidos, el Reino Unido y Canadá, ha sido el cambio de los hombres desde su papel de proveedores económicos hacia el papel de padres ausentes. Pese a que esto debe contextualizarse en términos de impacto en lo étnico, clase social, edad, orientación sexual y capacidades, los padres ausentes se describen con frecuencia en forma negativa como personas que descuidan sus responsabilidades económicas y emocionales hacia los niños ya sea que vivan o no junto a ellos o que estén o no involucrados en su cuidado.

En esta ponencia utilizamos un estudio que realizamos en Canadá Occidental sobre los padres a fin de plantear preguntas acerca de la capacidad de transferencia de conceptos desarrollados, esencialmente para ayudarnos a entender las relaciones familiares en occidente en relación a las de quienes pertenecen a otros lugares. Nos interesa descubrir cuáles son las cosas en común y cuáles las diferencias y si los conceptos, si es que existen en otras partes del mundo, significan lo mismo. Por lo tanto este taller tendrá componentes interactivos y esta ponencia debe considerarse como sin terminar hasta que este diálogo se le haya incorporado. La dificultad de conducir análisis comparativos ya ha sido identificada en la bibliografía de las ciencias sociales (Mahoney y Rueschemeyer, 2003), pero en el trabajo social existen problemas específicos que han de abordarse dado que su marco legislativo y cultural nacional están confinados a lo local, aún cuando éste se haya comprometido en aventuras de colonización (Lorenz, 1994; Dominelli, 2000, 2004).

Comenzamos por describir algunos de los asuntos y conceptos claves que nos interesaron en nuestro trabajo sobre los padres en el contexto canadiense y luego ofrecemos algunas de las conclusiones preliminares de nuestro estudio. Deseamos examinar los significados de diversos conceptos tales como 'los derechos de los padres' y 'las responsabilidades de las madres' en diferentes contextos y países. De este modo, un objetivo fundamental en esta sesión es el de explorar la forma en que podemos mejorar las comparaciones entre diversos países al centrarnos en la comprensión conceptual de los problemas y en qué tan bien (o mal) éstos atraviesan las fronteras.

\section{Establecer el contexto de esta investigación}

El 'Proyecto de los Padres' en el que se basa esta ponencia cuenta con el financiamiento de Social Sciences and Humanities Research Council of Canadá (Consejo de Investigación en Ciencias Sociales y Humanidades de Canadá). Es la continuación de estudios anteriores emprendidos por algunos de los autores sobre madres jóvenes con hijos bajo la protección del gobierno (Callahan y otros, 2002) y sobre el papel que los abuelos, (particularmente las abuelas) desempeñan en el cuidado de los niños (Brown y otros, 2004). En estos estudios notamos que los trabajadores sociales rara vez abordaron en forma directa a los padres de los niños en sus intervenciones en las situaciones familiares, incluso en aquellas raras ocasiones en que los padres desempeñaban un papel activo ayudando a las madres en la crianza de los niños, y nos preguntamos el por qué de esto. Un análisis de la literatura reveló que era poco lo que se sabía acerca de los roles paternales asumidos por hombres con hijos en el sistema de protección, ya sea que fueran éstos padres biológicos o cuidadores apoyando a las madres (ver Strega y otros, 2006). Esto nos planteó las primeras preguntas claves, a saber:

- ¿Quiénes eran esos padres (hombres)?

- ¿Qué se quería decir con el término 'padre’?

- ¿Qué roles jugaban los padres en las vidas de esas mujeres y/o niños?

- ¿Qué relación tenía estos hombres con las madres aparte de su rol materno?

- ¿Bajo qué circunstancias vivían estos hombres?

- ¿Con qué formas de apoyo contaban estos hombres?

Los discursos públicos acerca de madres y padres están profundamente sexuados, y se supone que las madres son las responsables de asumir el rol del cuidado de los niños en tanto que los padres se consideran con derechos respecto a sus hijos, pese a que pueden llegar a necesitar ayuda legal para hacerlos valer (Swift, 1995; Scourfield, 2003; Strega y otros, 2006). Nuestro análisis bibliográfico destacó una construcción que es en gran parte negativa de estos padres. Por lo general esta encaja dentro de los estereotipos de "buen padre" y "mal padre" 
destacados en un inicio por Furstenberg (1988). Los términos tales como 'padres ausentes' y 'padres que no cumplen sus responsabilidades de proveedores' fueron particularmente comunes en los discursos de políticas sociales (Orloff y Monson, 2002). Evidentemente, el incumplimiento de los padres de sus responsabilidades financieras como proveedores para los niños fue lo que primó en las mentes de los legisladores. También tuvo importancia en los discursos de los profesionales la capacidad de los hombres de actuar como 'modelos' ante los niños, en particular los niños varones (Kornfein Rose, 1992).

En nuestras conclusiones la descripción más apta de las relaciones de los trabajadores sociales con esos hombres fue la de 'padres invisibles'. En otras palabras, los trabajadores sociales los interpretaban como simplemente no teniendo presencia ya sea que realizaran contribuciones para el cuidado de los niños o no. En las construcciones de paternidad de aquellos padres vinculados con los profesionales de servicios sociales para la infancia, la invisibilidad de éstos contrastó con los altos perfiles otorgados a los hombres de clase media en donde los discursos tenían mayor probabilidad de centrarse en el 'padre involucrado' o 'nuevo' padre. Las madres jóvenes, que se ubican en otro ámbito, tuvieron mayor probabilidad de centrarse en las relaciones de los hombres con los niños y con su contribución en el rol parental (Haney and March, 2003). A partir del proyecto con las madres jóvenes supimos que incluso aún cuando las madres identificaron diversas formas de respaldo proporcionados por sus parejas, ya fueran estos padres biológicos o no, los trabajadores sociales las ignoraron (Dominelli y otros, 2005), una conclusión alcanzada antes por Scourfield (2003) y que se confirma en el presente estudio. El respaldo de estos hombres abarcó desde preocuparse por los niños para darle una pausa a las madres para que hicieran cosas personales hasta incluso vivir bajo el mismo techo plenamente comprometidos en el cuidado de los niños y contribuyendo económicamente.

Los trabajadores sociales se preocuparon más de los riesgos que estos hombres suponían para las mujeres y los niños, en particular si éstos tenían antecedentes de violencia, registros delictuales o de abuso de sustancias. Nuestra conclusión de que los trabajadores sociales no se involucraban activamente con la mayor parte de aquellos padres considerados 'riesgosos' para las madres y niños es preocupante y necesita ser abordada tanto por los profesionales como por las autoridades responsables de las políticas. Nuestro proyecto sobre las madres jóvenes demostró que la principal estrategia de los trabajadores sociales a la hora de lidiar con padres difíciles era sacar a los hombres de las vidas de las mujeres, a menudo forzando la decisión mediante la amenaza de retirar los niños en caso de que las mujeres se resistieran, y llevando esto a cabo cuando lo estimaron necesario (Dominelli y otros, 2005). De este modo el contexto y la persona que definía a estos padres tuvo peso en la forma en que estos eran descritos y en el cómo se reaccionó ante ellos.

En este proyecto, definimos como 'padres' a los padres de nacimiento (biológicos), padrastros y a aquellos hombres que proporcionaban respaldo financiero, emocional y social al (los) niño(s) en una relación (Strega y otros, 2006). Pese a que nuestro estudio sobre los padres se centró en un país, nos preguntamos qué tan lejos podrían viajar los términos utilizados para describirlos. Estos se evidenciaron con claridad en la literatura relativa a Australia, Canadá, el Reino Unido, Estados Unidos y Nueva Zelandia. Pero, isignificaban lo mismo estas palabras en estos países, y tenían las mismas connotaciones para las mujeres, hombres y niños implicados? ¿Qué terminología se utilizaba en países que no fueran de habla inglesa?, ¿tenía la paternidad la misma connotación al interior de sus sistemas de protección de la infancia? Estos son entre otros, algunos de los asuntos que queremos dilucidar en conjunto con los participantes en este taller. Y agradeceremos las contribuciones mediante correo electrónico de aquellos que quieran hacerlas. Por favor, envíen sus contribuciones a Lena.Dominelli@durham.ac.uk

\section{El estudio canadiense: conclusiones preliminares}

\section{Metodología de investigación y características claves de la muestra}

Pretendimos obtener un cuadro detallado y complejo de padres con niños en los servicios sociales de infancia y de sus relaciones con los profesionales de estos servicios, con los niños y con las madres de esos niños. Por lo tanto, nuestra metodología fue triangular e implicó tanto métodos cuantitativos como cualitativos. Estos incluyeron tanto análisis de cantidad como de calidad de los expedientes, entrevistas en profundidad de los padres y un análisis de los programas de estudio de los cursos de trabajo social a nivel universitario. 
Las madres y padres considerados en este estudio fueron aquellos vinculados a los sistemas de protección infantil, predominantemente pobres y marginales, tal como se ha documentado en otros estudios (Jones, 1994; Swift y Birmingham, 1999; Trocmé y otros, 2005). La muestra de 282 expedientes de niños bajo protección de este estudio se escogió de un total de 476 expedientes recolectados entre 1997 y 2005 en una agencia de protección infantil ubicada en una ciudad de tamaño medio en Canadá Occidental. El servicio social canadiense está a cargo de las provincias, por lo que es probable que cada jurisdicción mantenga algunas variaciones con respecto a las demás. Estas divergencias no se consideraron importantes en esta investigación. Para ser incluidas en esta investigación las madres debían tener 19 años o menos, p. ej, madres adolescentes, al momento del nacimiento de su primer hijo.

Creamos una herramienta estándar para captar la información a partir de un análisis de los expedientes seleccionados y realizamos una prueba previa de ésta sobre una cantidad pequeña de expedientes. Esta herramienta nos permitió el examen deliberado de los expedientes en busca de información tanto cuantitativa como cualitativa relativa a los padres. Realizamos un análisis cuantitativo de la muestra de 282 expedientes. De éstos, 163 se relacionaban con aquellos que recibían sólo servicios para futuros padres, 116 se relacionaban con los servicios de protección infantil y 3 no especificaron el tipo de servicios proporcionado y por consiguiente no se consideraron en el estudio. Sólo aquellos que figuraban en la categoría de protección infantil se utilizaron en el texto a continuación.

Cada expediente se examinó en busca de referencias de los padres. La recopilación de información implicó un examen de los registros de expedientes y otros materiales de éstos tales como documentos de juzgados, evaluaciones parentales y de riesgo, registros de trabajo social, cartas de referencia y otros documentos oficiales. Un paquete estadístico SPSS nos posibilitó el examen de la información en una variedad de formas. Estas conclusiones están en proceso de redacción, si bien la primera de ellas es la de Strega y otros (2006). También realizamos un análisis cualitativo sobre 24 expedientes que contaban con una buena cantidad de información sobre los padres.

Entrevistamos también a padres con hijos que estaban o habían estado bajo protección. Al momento de redactar esta ponencia habíamos realizado nue- ve entrevistas. La mayoría de estos hombres tenían antecedentes problemáticos o conflictivos y relaciones complicadas. Aquellos que entrevistamos respondieron a las peticiones de entrevista dispuestas en las agencias en donde pudieran encontrarse padres. Son, por lo tanto, un grupo auto seleccionado y una muestra incompleta. En consecuencia, las conclusiones cualitativas que surjan de las entrevistas en profundidad han de interpretarse con prudencia. No obstante, podríamos afirmar que lo que estos hombres dijeron es importante para plantear problemas e interesarnos en su posterior investigación y consideración. En el futuro entrevistaremos a más padres.

Como parte de este proyecto realizamos una encuesta de trabajo social calificando la carrera en Canadá, a fin de determinar la importancia del tema de la paternidad en la carrera de trabajo social. Abordamos 32 escuelas y obtuvimos una tasa de respuesta de 47 por ciento. Los resultados indicaron que las mallas curriculares de sólo algunas de estas escuelas consideraban en forma explícita a los hombres como padres, y que con frecuencia sus programas de estudio ni siquiera se referían a la limitada bibliografía disponible (Walmsley y otros, de próxima aparición).

\section{Algunas conclusiones preliminares sobre la información cuantitativa}

De los 116 expedientes de protección infantil analizados hubo 129 padres biológicos y 4 padres no biológicos. Los padres tendían a ser un tanto mayores que las madres por una cantidad de años que variaba entre 3 y 8 . En forma significativa, fueron más las madres ( 40 por ciento) que los padres ( 9 por ciento) que habían estado también bajo protección. Entre una cuarta parte y una tercera parte de los padres biológicos proporcionaba ayuda financiera o en especies. No hubo información disponible sobre los padres no biológicos. En estos expedientes la presencia de los padres aborígenes fue extremadamente alta.

Los trabajadores sociales consideraron que la mitad de todos los padres carecía de importancia tanto para las madres como para los niños, y que el 20 por ciento de ellos se definía como un riesgo tanto para las madres como para los niños. Al mismo tiempo, se consideró como recurso a un 20\% de los padres. Los trabajadores sociales contactaron sólo a $40 \%$ de los padres biológicos considerados un riesgo para los niños, dejando sin contactar a la mayor parte de aquellos hacia los cuales se expresaron mayores preocupaciones. No obstante, entre aquellos 
padres estimados como recurso, los trabajadores sociales contactaron 75 por ciento de aquellos. Como la información se recopiló en un sólo lugar, no es posible generalizar a partir de nuestras conclusiones. Sin embargo, sospechamos que éstas resonarán en algunas de las demás jurisdicciones.

\section{Algunas conclusiones preliminares sobre la información cualitativa}

Nuestro análisis cualitativo implicó el estudio de 24 expedientes que contaban con una considerable cantidad de detalles acerca del contacto de los trabajadores sociales con los padres. En general este proyecto reveló que la mirada de los trabajadores sociales se posa en forma constante sobre las madres. Dentro del contexto de la invisibilidad de los padres que se destaca en esta investigación, los trabajadores sociales utilizaron a las madres como conducto para averiguar sobre ellos o para contactarlos en la mayoría de los casos. Es así como la madre se vuelve responsable de manejar el comportamiento del padre junto con sus deberes de cuidar, alimentar y satisfacer de alguna manera las necesidades de los niños. También resulta ella la responsable si las cosas salían mal. Además, los trabajadores sociales esperaban que las madres siguieran por ellos el rastro a los padres en lo que podría considerarse como una vigilancia por tercería. Es así como la madre se convierte en mediadora de la relación entre el trabajador social que representa al Estado, el padre y los niños.

Consideramos que esto no era apropiado y quisiéramos animar a los profesionales a contactar en forma directa a los padres, ya sea que los consideren un riesgo o un recurso, y que los evalúen para tener una idea de qué intervenciones son necesarias para proteger a las mujeres y a los niños de los daños cuando hay probabilidad de que éstos ocurran, y que ayuden a los hombres a lidiar con sus dificultades ya sea que se relacionen éstas con la violencia, el abuso de sustancias, comportamiento delictual o con su incapacidad de establecer relaciones significativas con las mujeres y los niños. Los pocos padres que entrevistamos señalaron que estaban concientes de los riesgos que enfrentarían de comportarse en forma inapropiada. El temor a perder contacto con los niños jugó en esto un papel crucial. Pensamos que esto puede ofrecer una base desde la cual comprometer a los hombres en un cambio intencional que podría mejorar su capacidad de relacionarse con las mujeres y los niños de maneras no abusivas. Nuestra investigación, sin embargo, demostró que si los trabajadores sociales notaban la presencia de los padres, era principalmente en términos de imponer sus derechos, en cuyo caso se le recomendaba a éstos que 'consiguieran un abogado' en lugar de realizar un trabajo directo con ellos para abordar sus problemas de relaciones interpersonales y familiares.

A nosotros, la conclusión acerca de la falta de compromiso de los trabajadores sociales hacia los padres nos planteó dudas acerca de lo apropiado de la educación y capacitación en trabajo social a la hora de preparar a profesionales para que trabajen con hombres que les suponen desafíos y que además pueden significar una amenaza para su propia seguridad. Para investigar qué se estaba haciendo a este respecto realizamos la encuesta mencionada antes sobre la carrera.

A continuación presentamos percepciones que surgieron de las entrevistas realizadas hasta este momento a padres con experiencia en el sistema de protección infantil, lo que nos posibilita expresar algunas de sus preocupaciones en sus propias palabras. La poca expresión que se les permite a los padres con niños bajo custodia del sistema de bienestar infantil es algo que Tyrer y otros (2005) también señalan en el Reino Unido.

Los padres sufrían de formas específicas de exclusión y marginación, que llamaron nuestra atención durante las entrevistas. Éstas incluían:

- La falta de consulta en los procesos en los cuales los niños eran tomados en custodia ya sea en hogares de acogida o con objeto de darlos en adopción.

- Explicaciones inadecuadas acerca de los procedimientos que los trabajadores sociales utilizaban para tomar decisiones acerca de los niños.

- Contacto insuficiente con los niños, ya sea que estuvieran éstos al cuidado de las madres, cuidadoras u otras formas de cuidado proporcionado por instituciones.

- Fracaso en cubrir la brecha informativa entre las rutinas diarias que seguían los padres adoptivos y aquellas que se aplicaban cuando los niños visitaban a sus padres.

- Falta de consulta respecto de la crianza de los niños en general.

- No ser informados sobre sus derechos de acceso, custodia, ni de la forma en que podían cuestionar las decisiones de los trabajadores sociales. Algunos entrevistados se quejaron de que sus abogados tampoco los prepararon y 
ni los respaldaron en forma apropiada durante los procesos legales.

- Falta de servicios de apoyo en la crianza de los niños aún cuando mantuvieran la custodia o fueran ellos los únicos cuidadores.

Para los hombres entrevistados la paternidad, o ser un padre para sus hijos, era importante. Algunas veces se hizo uso de pruebas de ADN para establecer a un hombre en particular como padre y para establecer o limitar sus responsabilidades legales en proporcionar apoyo. En otras oportunidades los hombres la usaron para asegurar que no se les negara su potencial de actuar como un padre o papá activo. Aquellos hombres comprometidos con ser el padre 'involucrado' insistirían en su petición de involucrarse con los niños, incluyendo el someterse a una prueba de ADN o el resolver los conflictos con las madres para establecer la paternidad y asumir responsabilidades en la crianza de los niños.

Se determinó que algunos padres se conformaban con el rol de padre proveedor o sostén de la familia. Tanto Tyrer y otros (2005), como Scourfield (2003), descubrieron esquemas similares en el sistema británico. También concluimos que los hombres deseaban omitir a las madres "ausentes" o "excluidas" para asumir ellos el cuidado de los niños si es que pensaban que una situación lo justificaba. Así lo expresó en nuestro estudio un padre a cargo de la custodia del niño:

'Amo a mis hijos. Lo quiero todo para ellos.

Pero no, no quiero tener nada que ver con su madre'.

En lo fundamental, los padres en este proyecto que tuvieron contacto con trabajadores sociales no los encontraron de mucha ayuda, una conclusión que se repitió en el estudio de Tyrer y otros (2005). Y había poca confianza entre los trabajadores y los padres, un ingrediente de suma importancia en la creación de relaciones. Los padres de nuestra investigación sentían que los trabajadores sociales tenían bajas expectativas respecto a ellos y que con frecuencia los mantenían vigilados, esperando que fracasaran en cumplir con sus responsabilidades o que se involucraran en actividades por las cuales se les podría negar el contacto con los niños. A continuación se exponen algunas de las preocupaciones expresadas en las propias palabras de los hombres:

'Tuve asistentes, pero ellos sólo esperaban que yo echara a perder las cosas'.

¿Por qué estoy siendo espiado? Al primer error que cometa, pssst'.
'Les dije que de la forma en que ellos (los trabajadores sociales) me hacían sentir es como si nunca hubiese sido su padre'.

'Sentía que tenía que probarme a mí mismo y que... ... tenía que ser supervisado. Como lo estaba, como si tuviera una cuidadora (una cuidadora infantil para el padre)'.

Otro padre afirmó que el sistema era abusivo con respecto a las discapacidades. Dijo:

'Tuve (trabajadores sociales) a quienes no les gustó que yo fuera VIH positivo. Tuve asistentes de discapacidad a quienes no les gusta que yo sea VIH positivo. Trataron de quitarme el subsidio porque piensan que no debería tener un hijo'.

En ocasiones el juzgado se ponía del lado de los hombres. Esto podía ocurrir en las historias de vida de hombres con antecedentes de relaciones deficientes con trabajadores sociales o con otros profesionales dedicados al bienestar de los niños. En nuestra investigación así resultó ser en el caso de un hombre que salió de la cárcel luego de haber cumplido su sentencia y que se involucró en el cuidado de su pequeña niña mientras la madre salía 'a divertirse'. Según el hombre entrevistado, la relación entre el padre y la madre se había deteriorado debido a que la madre se había involucrado con otro hombre. Así lo expresó él:

'Me convertí en el único proveedor de mi niñita. Desde ese momento presenté una demanda por la custodia -la obtuve'.

Volvieron a unirse por un periodo y tuvieron otra hija antes de separarse definitivamente. Él estaba luchando por la custodia de la segunda hija al momento de la entrevista. Con todo, sentía que no contaba con apoyo de nadie cuando la madre lo molestaba, especialmente cuando ella había bebido y quería ver a las niñas y él se negaba a dejarla entrar a la casa. Pese a dar cuenta de esta conducta, que incluía el hecho de que ella rompiera ventanas de la casa, el hombre sostuvo lo siguiente:

'Llamé tantas veces por teléfono a la policía, y me daban los números de informe de incidente, pero usted sabe, si hubiera sido una chica y yo la hubiese estado molestando, yo estaría preso... nunca recibí de ellos apoyo ni cosa alguna'.

Su historia hizo surgir el tema del 'papá víctima', que también se repite en otros. Con toda claridad se veía a sí mismo como víctima de instituciones pú- 
blicas que le negaban apoyo, en particular aquellos profesionales relacionados con el sistema de bienestar infantil y con el sistema de justicia criminal. Y se veía sólo reaccionando a la agenda establecida por su poderosa pareja, p.ej., él también era su víctima. Concluyó de esta manera:

'Así que donde sea que acuda es siempre mi culpa y no puedo obtener justicia. El juzgado no me dará una orden de restricción ni nada, de modo que no sé. No puedo presionarla porque me metería en problemas. Si llegara a tocarla una vez sería culpa mía. Así que he tenido que mudarme cuatro veces para apartarme de ella pero ella sigue sabiendo dónde encontrarme. Así que seguro que tendré que mudarme otra vez... ella va a perseguirme porque es de esa clase de personas'.

Uno de los padres que luchaba por tener acceso a su hija expresó sus frustraciones ante lo que había experimentado como un sistema poco empático de la siguiente manera:

'Estoy tratando de superarme (estaba tomando un curso). Usted sabe, así que hice todo lo que se me dijo que debía hacer... Entonces, quiero decir que es una situación de perder. Perder, perder, perder... Así que me apegué a lo que me mandaban tal como se me pedía, haciendo todo lo posible para ver a mi hija'.

Otro tema que surgió fue el de los padres que se sentían víctimas del sistema. Así lo expresó uno de ellos:

‘...Nunca imaginé el poder que tenían para quitarme a mi niña.... Ellos (los vecinos que habían llamado a la policía porque su esposa se había desmayado en el pasto por beber demasiado) habían llamado a la policía, dos oficiales ahí, estoy llorando como un niño, ahora que me doy cuenta de su autoridad para quitarme de los brazos a mi hija basándose en los rumores. Basándose en el hecho de que mi esposa hizo algo. Como el padre (él mismo) estaba donde debía estar. La niña estaba donde debía estar (en la cama). Ninguno de nosotros hizo ningún perjuicio. La casa estaba limpia. No había motivos (para que intervinieran)'.

Para algunos, ser la víctima produce resultados traumáticos. Un padre, que actualmente está en tratamiento antidepresivo y que no puede encontrar empleo como resultado de la lucha con su ex pareja por los niños, declaró el haber desempeñado el papel de víctima para mantener el contacto con los niños:

'...descubrí que mi novia me trataba con puño de hierro en esa relación. El síndrome de haz esto o aquello. ...Es lo esencial del quiebre de la relación, con muchos, muchos ultimátum y amenazas y tratando de mantener la relación y hacer que las niñas siguieran en mi vida'.

Varios hombres hablaron de la falta de continuidad con los trabajadores y de las alteraciones que esto les había provocado. Podían haber tenido una buena relación durante un tiempo con un trabajador social en particular (y por lo tanto con la agencia que él o ella representaba), pero esto se acababa al irse el trabajador. La falta de continuidad institucional y las inapropiadas (o ausentes) sesiones de entrega pueden producir el empeoramiento de las relaciones entre los trabajadores sociales y los padres. Un hombre declaró que su 'nueva' trabajadora social sólo se interesaba en estipular que él era un 'mal papá', diciendo lo siguiente:

'Ella (la nueva trabajadora social) quiere que yo falle pues piensa que puedo fallar'.

Esto hace eco de la percepción de Furstenberg $(1988,1995)$ en relación a que las políticas públicas decepcionan con frecuencia a los padres al clasificarlos en el esquema binario de 'buen papá - mal papá'. Los padres de nuestro estudio afirmaron que necesitan buenas relaciones tanto con los trabajadores sociales como con los asistentes y que sentían que podrían contar con su apoyo y habilidades de facilitadores, especialmente al mediar las relaciones entre ellos y los cuidadores adoptivos. Pero encontraban que estas habilidades rara vez se exhibían. Uno de los padres que entrevistamos lamentó la poco adecuada comunicación entre las diferentes partes del sistema de bienestar infantil y él, lo que trajo consecuencias en su cuidado del niño. Dijo:

'Ni siquiera sé cuál es el nombre de la madre adoptiva... ni siquiera sé lo que ocurre en esa casa ni cuál es su programa... ella no interactúa conmigo, ni me escribe cartas ni por último alguna nota acerca de lo que a ella (la hija) le gusta'.

Así, sus razones para desear ese contacto eran entendibles y estaban relacionadas con su deseo de hacer lo mejor posible con su hija. Dicho en sus palabras:

'Quiero conocer su rutina de modo que tal vez pueda imitarla...mantener la rutina que 
ella ha empleado en lugar de traerla a un entorno completamente nuevo'.

Algunos trabajadores sociales buscaron evitar el contacto con aquellos que consideraron hombres potencialmente problemáticos o complicados. En esos casos el pedido de los hombres de una llamada telefónica de los trabajadores se ignoró. Esta probabilidad aumentó en el caso de los hombres con antecedentes de violencia, uso de drogas o con registros delictuales. Si los padres conocían esta configuración de su presencia fueron bastante flemáticos con respecto a ella. Así lo expresó uno de ellos:

'Se supone que no tenga contacto con el trabajador social por las razones de seguridad que usted sabe. No consigo su número de teléfono, ni nada'.

También encontramos evidencias del padre subestimado. Los trabajadores sociales subestimaron la voluntad o la capacidad de los hombres de ser padres adecuados, aún cuando éstos habían tenido que sobrellevar circunstancias difíciles que incluían aquellas en las que el (los) niño/s tuvieron diversos problemas como resultado del mal uso de sustancias por parte de la madre durante el embarazo. Dicho en las palabras de uno de los padres:

'Estoy preparado para su SAF (Síndrome de presencia de alcoholismo en el feto), lo estoy sobrellevando, pero por la forma en que me hacen sentir, los servicios para el niño y para a familia, es como si yo no estuviera calificado para ser ningún tipo de padre'.

El padre, que había estado cuidando a una pequeña niña que sufría del SAF y que tenía un amplio rango de necesidades médicas, o una niña que precisaba muchos cuidados, según lo estimaba él, sostuvo que:

'Ella (la trabajadora social) no se da cuenta que la he cuidado (a la hija) durante los últimos 3 años y que he ido a todos los médicos, he pasado por todos los dolores y dificultades y meteduras de pata y, usted sabe. Es como si yo fuera el Sr. Mamá, pero ella no se da cuenta. Usted sabe, sólo porque yo soy un tipo ella se imagina, $\mathrm{OH}$ ! bien, él simplemente va a hacer cualquier cosa'.

Ninguno de los padres que entrevistamos tuvo elogios para referirse al sistema de bienestar infantil por la forma en que éste había educado a los niños. Algunos pensaban que había sido muy negativo. Dicho en las palabras de uno de ellos:
'Ellos hacen lo que quieren hacer y pienso que todo ese impacto, con los años, ha traumatizado a los niños'.

Otro padre que enfrentaba una demanda de su pareja por abuso sexual de los niños (que luego se estimó como falsa acusación en el juzgado) y por el derecho a visitas relacionó la acusación de la madre con un sistema coludido con las madres. Dijo:

'Los padres son.. una carta fácil de jugar para las madres cuando ellas tienen muchos deseos de desquitarse y de ser muy desagradables con sus ex parejas. Me refiero a que ya hace un año que perdí a mis hijos. Ha sido un año de angustia mental por la que he pasado, audiencias en el juzgado, dinero, tuve que pagar abogados... y a ella nunca se le dijo nada'.

Algunos padres también sentían que habían estado sometidos a la vigilancia de los trabajadores sociales y a interminables investigaciones por falsos motivos. Más aún, pensaban que si se les hubiese investigado una vez, siempre se los habría estigmatizado y calificado como inadecuados independientemente de lo que hayan hecho. Uno de estos hombres afirmó:

'Una noche tomamos, y alguien llamó a (los servicios) para la infancia y la familia y (nombre de agencia) llegó y vieron un montón de botellas de cerveza. Informaron a (nombre de agencia) y (nombre de agencia) vino al día siguiente y dijeron que se llevarían a nuestros niños. Así empezó todo. Ha sido una lucha constante'.

Él y su pareja habían luchado contra el sistema de bienestar infantil para recuperar a los niños durante más de 10 años. Habiendo entregado 7 niños a las cuidadoras temporales y a pesar de un proceso judicial pendiente sobre el menor de los niños, el padre afirmó que:

'Me temo que va a ser otro proceso'.

La preocupación respecto al ciclo de privaciones y padres pobres se hizo evidente en el proyecto de madres jóvenes que emprendimos (Callahan y otros, 2002; Dominelli y otros, 2005), y también aparece entre los jóvenes padres mencionados en Trocmé y otros $(2003,2005)$. Como padres provenientes de las Naciones Originarias, el hombre de nuestro estudio se sentía tratado en forma particularmente injusta. Pero sus intentos de quejarse o incluso buscar alguna reparación legal quedaron en nada. Sentía que los profesionales del bienestar infantil habían intentado engañarlo con intervenciones in- 
significantes. Cuenta su historia en los siguientes términos:

'Otras familias obtienen un mejor trato. Me quejé. Le dije a mi abogado que me parecía que eran racistas... es muy difícil durante 10 años tratar de mantenerse en calma y hablarles en forma racional. A veces siento que voy a explotar. En el pasado ya lo hice. Ellos (los trabajadores sociales) me dijeron que necesitaba aprender a controlar mi rabia'.

Este hombre también destacó el diferente trato que percibió respecto de las Familias de Naciones Originarias, dependiendo de si estaban dentro de reservas o fuera de ellas. Y sostuvo que los Metas, que son en parte aborígenes y en parte blancos (Canadienses franceses) obtenían incluso peores tratos que aquellos con orígenes nativos 'puros'.

La falta de apoyo institucional para los padres parece algo típica y puede considerarse como negligencia institucional'. A veces las restricciones sobre los recursos limitaron el respaldo que los trabajadores sociales podían ofrecer. Por ejemplo a un padre se le negó un curso de control de la ira 'porque no entraba en el presupuesto'. Los hombres, dejados a su libre albedrío, improvisan lo mejor que pueden sobre lo que ellos experimentan como circunstancias complejas, aislantes y desconcertantes. Otro padre expresó sus frustraciones respecto al sistema de la siguiente manera:

'(Yo) en verdad estaba yendo tras el Ministerio lo mejor que podía ¿con qué? Básicamente, no tenía ningún conocimiento. Tuve que creerle a un abogado que era de la Asistencia Legal y a Internet e intentar interpretar la ley familiar lo más que mi capacidad me permitió y la legislación tal como la lleva el Ministerio, usted sabe, su interpretación de la legislación'.

\section{Preguntas para los participantes del taller}

Nuestro proyecto destacó la importancia y posiblemente puso a prueba la naturaleza de los siguientes conceptos que quisiéramos explorar junto a los participantes del taller:

\section{Madres/Roles maternos/ Estereotipos}

Padres/Roles paternos/ Estereotipos

Derechos de los padres

Padres como víctimas
Padres como personas no valoradas

Responsabilidades de las madres

Negligencia institucional

Riesgos

Recursos

Invisibilidad

Vigilancia

Vigilancia por terceros

¿Hasta qué punto estos términos portan un significado para quienes viven en otros países?

¿Pueden usarse estos términos para realizar comparaciones entre varios países?

¿Cómo pueden llevarse a cabo en mejor forma las comparaciones entre países tratándose de una disciplina específica de un país, como la del trabajo social?

\section{Conclusiones}

Las historias presentadas por los padres en nuestro estudio fueron historias de oportunidades perdidas para que los profesionales del bienestar infantil se comprometieran con ellos en pro del 'mejor interés del (los) niño/s)'. Las consideraciones relativas al 'riesgo' para las madres, niños y profesionales pareció tener más peso que aquellas que implicaban pensar en forma creativa acerca de lo que los padres podían ofrecer y acerca de qué otras condiciones aparte de la falta de contacto respaldaría mejor los derechos de los niños de relacionarse con ambos padres en seguridad y tranquilidad. Uno de esos hombres explicó su caso en forma sucinta:

'Pareciera que ellos (los trabajadores sociales) están ahí fuera para sí mismos y para mantener alejados a los niños. Pareciera que no tienen mucho ingenio para unir a las familias'.

Para nosotros, esto expone la necesidad de 'reconfigurar' la comprensión que predomina acerca de los padres y cuestionar las imágenes que los tratan como poco interesados en el bienestar de los niños. Al mismo tiempo estamos concientes de la necesidad de ejercitar la sensibilidad y la prudencia para no oponer los derechos de las madres a los de los padres; o los derechos de los adultos a los de los niños.

Nos interesa saber qué tanto resonarán estas conclusiones entre otros educadores y profesionales, y si los conceptos que hemos usado para analizar esta 
investigación tienen resonancia en otros lugares. Como se espera que esta ponencia obtenga respuestas de los participantes del taller (o de otros, a través de Internet) y que proponga ideas acerca de cómo realizar mejor la investigación a través de diferentes países en el futuro, esperamos poder tener una provechosa conversación sobre los temas que hayan surgido de esta ponencia. ¿Cuán lejos pueden llegar los conceptos y entendimientos desarrollados en una jurisdicción dentro de otra? ¿Estamos haciendo comparaciones entre similares? ¿Necesitamos desarrollar nuevos marcos conceptuales? De ser así, ¿cuándo y dónde podemos llevar a cabo esas actividades? Las nuevas tecnologías de la información pueden ofrecernos una manera de avanzar. Pero por lo menos, comencemos a dialogar.

\section{Referencias}

BROWN, L, CALLAHAN, M, WHITTINGTON, B Y MCKENZIE, P. (2004) Grandmothers and Child Care in the Family. Proyecto con financiamiento de SSHRC (Consejo para la Investigación de las Ciencias Sociales y Humanidades, Universidad de Victoria, Victoria, B C.

CALLAHAN, M; DOMINELLI, L; RUTMAN, D AND STREGA, S. (2002) 'Undeserving Mothers: Lived Experiences of Young Mothers In and From Government Care' In Child Welfare: Connecting Research, Policy and Practice published by Kathleen Kufeldt and Brad McKenzie. Waterloo, Ont.: Wilfrid Laurier University Press, pp. 249-260.

DOMINELLI, L. (2000) 'International Comparisons in Social Work' In Innovative Education and Training for Care Professionals: A Providers' Guide publicado por Rachel Pearce y Jenny Weinstein. Londres: Jessica Kingsley, pp. 25-42.

DOMINELLI, L. (2004) Social Work: Theory and Practice for a Changing Profession. Cambridge: Polity Press.

DOMINELLI, L, STREGA, S, CALLAHAN, M Y RUTMAN, D. (2005) 'Endangered Children: The State as Failed Parent and Grandparent', British Journal of Social Work, 35(7):1123-1144, Oct.

FURSTENBERG, F. (1988)' 'Good Dad- Bad Dad: The Two Faces of Fatherhood' in The Changing American Family and Public Policy publicado por Cherlin, A J. Washington, DC: Urban Institute Press.

FURSTENBERG, F. (1995) 'Fathering in Inner Cities' sobre Fatherhood publicado por W Marsiglio. Thousand Oaks: Sage.
HANEY, L Y MARCH, M. (2003) 'Married Fathers and Caring Daddies', Social Problems, 50(4):461-481.

KORNFEIN ROSE, M. (1992) 'Elective Single Mothers and Their Children: The Missing Fathers', Child and Adolescent Social Work Journal, 9(1):21-33.

LORENZ, W. (1994) Social Work in a Changing Europe. Londres: Routledge.

MAHONEY, J Y RUESCHEMEYER, D. (2003) Comparative Historical Analysis in Social Sciences. Cambridge: Cambridge University Press.

ORLOFF, A Y MONSOON, R. (2002) Making Men into Fathers. Cambridge: Cambridge University Press.

SCOURFIELD, J. (2003) Gender and Child Protection. Londres: Macmillan.

RUTMAN, D, STREGA, S, CALLAHAN, M Y DOMINELLI, L. (2002) 'Undeserving Mothers? Practitioners' Experiences Working with Young Mothers In/From Care' in Child and Family Social Work, 7:149159.

STREGA, S, FLEET, C, BROWN, L, DOMINELLI, L, CALlAHAN, M Y WALMSLEY, C. (2006) Connecting Father Absence and Mother Blame in Child Protection Policies and Practices. Ponencia no publicada, distribuida en el Encuentro Programático Anual del Consejo de Educación en Trabajo Social, en Chicago, Febrero 28. Puesto a disposición por los autores.

SWIFT, K. (1995) Manufacturing Bad Mothers. Toronto: McClelland y Stewart.

TROCMÉ, N, KNOKE, D, Y BLACKSTOCK, C. (2004) Pathways to Over-Representation of Aboriginal Children in Canada's Child Welfare System. Ottawa: First Nations Child and Family Caring Society of Canada.

TROCMÉ, N, KNOKE, D, FALLON, M, MACLAURIN, DACIUM, FELSTINER, (2005) Staying at Home. Ottawa: First Nations Child and Family Caring Society of Canada.

TYRER, P, CHASE, E, WARWICK, I AND AGGLETON, P. (2005) 'Dealing with it:' Experiences of Young Fathers in and Leaving Care', British Journal of Social Work, 35(7):1107-1121.

WALMSLEY, C, BROWN, L, CALLAHAN, M, DOMINELLI, L, STREGA, S. (de próxima aparición) Coverage of Fatherhood in the Curriculum in Canadian Schools of Social Work. Victoria, BC: University of Victoria, School of Social Work, Ponencia no publicada. 